\title{
Su Dongpo Huangzhou Period of Health Care
}

\author{
Libin Yu* \\ Institute of Physical Education, Huanggang Normal University, \\ Huangzhou 438000, Hubei, China
}

\begin{abstract}
Su Dongpo is recognized as the most outstanding master of literary and artistic attainments, and one of the representative figures of the elegant culture. After he was banished to Huangzhou's period, he joined the Buddhist monastic, his outlook on life and principle of life has changed dramatically. Henceforth, he used poetry, words, odes, letters, paintings and the elegant culture to chase away his gloom in the heart and get rid of the predicament of life, which had reached the realm of enjoying nature's endless treasure "travel with the creator", which is from a poet of the Tang Dynasty, Liu Zongyuan's poestry "The First Visit To Western Hills Notes", which opened the journey of elegant living in his life. This article discusses his elegance and regimen from the two dimensions of Su Dongpo's calligraphy, paintings, and poetry, words, odes, letters during the huangzhou's period. Those are not only a positive meaning to carry forward Chinese culture and build a complete system of the Su's literature, but also a benefit to shape the people's literary, enhance the spirit of the times, and lead people to a healthy life.
\end{abstract}

Keyword: Su Dongpo; Huangzhou; Elegant culture; Regimen

\section{INTRODUCTION}

The elegant culture is in the process of labor and human activities, with "elegant, classical, quiet, gentle" featured culture. In the history of art and literature in China, Su Dongpo is the most outstanding recognized literary and artistic attainments of everyone and elegant culture is one of the representatives. His poems, fresh and bold, quiet and reserved, He and Huang Tingjian were called as "Su Huang", and Lu You was called "Su Lu". His words, break through the traditional fetter, the reform of the late Tang Dynasty and Five Dynasties "graceful style, create a bold faction, he and Xin Qiji was called"Su Xin". His prose, freely, bold and unrestrained, and great momentum, such as sea waves, he and Han Yu was called "Han tide Su sea"; equal emphasis on literary and Taoism, show the attitude, grand and magnificent, and Ou Yangxiu was called "Su Ou". His handwriting is simple and powerful, majestic and grand, "Reveal feelings without restraint ", and Huang, Mi, Cai were called "Four masters of Song Dynasty", his representative works 《poetry for Huangzhou》 was Known as the "third cursive script of the world ". His paintings, rich temperament, elegant taste, created a style of Huzhou painting, he and Wen Tong were called "Wen Su". However, our understanding of Su Dongpo, mostly concentrated in the aspect of his elegant culture, about he in Huang Zhou to put his heart in leisure, with elegant culture to health, know little. Explore the journey of Su Dongpo in Huangzhou period, to understand the causes of elegant culture, we can understand significant his health thought of elegant.

\section{The Reason of Su Dongro's Elegant Culture in Huangzhou Period}

Yuanfeng two years (1079), Su Dongpo "text slander monarch" charges, was banished to WuTai, in jail for 103 days, during which several times almost beheaded. Thanks to the song country, set the policy not to kill the literati, Su Dongpo was lucky to escape the catastrophe. After his release, Su Dongpo was demoted by Huangzhou, reduced to eight items from the Huangzhou militia Fushi. After this incident, suffered a serious political blow, Su Dongpo was like "The frightened bird", for the first time felt the" lonely sandbar cold "[2], entered into the first inflection point of life.

\footnotetext{
"Corresponding Author: Yu Libin, male, born in August 1967, Professor of Huanggang Normal University Sports Institute ,also is a Master Tutor, mainly engaged in the folk sports research of EDong. Address: No43 Xingang second Road, Huangzhou District,Huanggang City, Hubei Province, Huanggang Normal University Institute of physical education,Zip code: 438000.
} 
Yuanfeng three years (1080) the beginning of the February, Su Dongpo demoted to Huangzhou still suffering from the shock, he "closed door, reflect old mistakes" [3]. In a period of time, he "abandoned pen ink stone" [3], "no longer wrote poetry and words as before" [4], afraid of the past," exploited by people with bad heart" [4], to give birth to a lot of trouble. Demoted to live in Huangzhou early, he was always alone, "self reflection" [5], thought his terrible scene nowadays, because the past like "talking about interest, and talk about gain and loss" [5]. So, he "has nothing to go out "[3], thinking about the future of life to meditation. He thought political views that was" not keeping pace with the times "[6], has not been to court" new ", today in the hall, no longer have a place to live in, the political future is uncertain, he wash heart change"

Early is the heart of the world, an official is small but concerned the people "[7], devoid of feeling, face the sad reality. Yuanfeng three years (1080) in the second months, He wrote to the Qin Guan:"I'm gradually aging that can not like a teenager, now with the Taoist method of self health". During the period of exile had no things, learn about one or two. I had borrowed three Taoist temples from Tian Qin of local state. In winter, just enter the room, forty-nine days before coming out. ...... Once filled this period, it has been established "[8]. Su Dongpo "self-learning"[8] in Tian Qin of Huang Zhou, not only for health considerations, but also to "fundamental" ideology and the establishment of a new attitude and life style. In addition, he every one or two days, "morning to night back" [9]to Huangzhou Anguo temple incense meditation, to realize the true meaning of life, and soon after, gradually have been obtained, and the value of life, made a new interpretation. To Yuanfeng three years (1080) at the end of the year, he write to Li Duanshu and said:"You see me in the past, not the present. "[5]. Su Dongpo at this time, almost completely, can do" The matter has already returned to the heart"[8], no longer made the success and fame as the value of life choice. He usede tried to make a start, and used the Buddha and devout to calm, detached heart resentment, restore the spirit vitality. Later, he also be upgraded to super open to indifferent, contented yourself, to dispel melancholy and free of worries. And Yuanfeng four years (1081), youth potential "detached from things" thought, in Su Dongpo heart, healthy growth, "the Yangtze River around the castle, the river fish taste delicious, lush bamboo shoots all over the mountains and plains was blowing people incense "of " optimistic "concept, quietly blooming, open-minded uninhibited feelings, came into being. To Yuanfeng five years (1082), his experience of life and death and learn the spirit of nutrition after baptism of new Su Dongpo, completely out of the predicament, the outlook on life, world outlook happened to turn the world upside down changes, elegant culture creation, reached a hitherto unknown peak. This year, he made in March 7th 《storm. Not to wear forest leaf sound》, in food festival wrote 《The poetry of Huangzhou Hanshi》, later wrote 《HuanSha river. at the foot of the mountain just grew out of bud soaked in water》, wrote 《Song of the Red Cliff》 on July 16th, then made 《stories at Chibi》, October 16th he made 《Post Chibi Fu》. Since then, Su Dongpo completely put down the heart block, with extraordinary empty clear, combined elegant culture and health closely, in the creation of Huangzhou resolve depressed, emotional catharsis to health of the poetry text, more than 740 articles.

\section{Su Dongpo Huangzhou Period of Health Care}

During the period of Huangzhou, although Su Dongpo has thought of Confucianism as the spiritual support, but the adjustment of boredom, cultivated his mind, still needs his love of elegant culture to vent and express. As he said himself: "a life without pleasure, only wrote essay, When wrote the heart to write twists and turns, it made me cheerful, I thought it is a pleasure and no more than it. "[10] From it, he opened his thought about Huangzhou period of health car.

\subsection{The Elegant Health of Painting and Calligraphy}

In terms of calligraphy, in ancient China cultural prosperity of the Song Dynasty, Su Dongpo led calligraphy a thousand years old, Create a tradition of "Jin take rhyme and Tang take method", [11] Pursue a new situation that individuality liberation "take the situation"of calligraphy . As "a leading figure in the art of calligraphy" of Su Dongpo, his calligraphy was not only show features of regardless of the merits and Vigorous and broad, but also revealed a longitudinal bold, flat and innocent nature of life. Su Dongpo in Huangzhou period created a peak of the work 《The poetry of Huangzhou Hanshi》, was full explanation of the rich connotation. In terms of painting, Su Dongpo stressed style charm, or not shape, advocated moral and expressed meaning, used meaning expressed feeling, express sincere heart charm. He criticized the old folk painting, first put forward the "literati 


\section{Su Dongpo Huangzhou Period of Health Care}

painting", advocate" the requirements and laws of art poetry and painting are the same, it is natural for fresh and natural"[12], he thought " if painting can only shape, which is similar to the child's level of [12]. "

Su Dongpo in Huangzhou also believes that painting is not only an art, but also a good health method, it was good for restoring the spirit and exercising body. As far as restoring the spirit concerned, $\mathrm{Su}$ Dongpo in Huangzhou advocate that calligraphy is reflection in which calligraphers of moral knowledge and moral cultivation in the book. Talking calligraphy should be "talk about their life as the same time "[13], emphasizes the value of calligraphy, calligraphy works depends on the inherent charm and style. This kind of charm and style, have a greater role to restore the spirit. (Song)Zeng Minxing in 《alone awake magazine. third volumes》 recorded a story, from one side illustrates this problem. One day Su Dongpo said to Huang Tingjian, "your handwriting is too thin, like the trees a few snakes." Huang Tingjian said: your words are fat and flat, "like a stone pressure toad."Then, they were laughed. In painting, Su Dongpo was good at painting dead wood, clubs, bamboo and stone. Living in exile in Huangzhou, he used his pen to write out the interwoven in the hearts of the frustration of the gas, in order to drainage in dish and ease the sorrow. As the surviving paintings 《The drawing of dead wood and rocks》, "the branches like Qiulong same winding, no beginning and end "[14], "like his heart's melancholy"[14], that seemed to struggle stretching of the tree, showing aloof weird gas, just as Su Dongpo stand out and independent character, enjoy the release of mind. It is in the period of Huangzhou physical exercise, Su Dongpo believes that "write often to practice "[15], to standstill, the force through the paper;painting to "draw the spirit"[15], "like nature itself"[16], the only way to "the full of charm" [15], reached the results that"the heart, eyes and hands all arrive"[13]. Su Dongpo in Huangzhou that the brush on the paper to do all kinds of painting and calligraphy movement, although very soothing, but temper body effect is very obvious, is a good recipe for health.

\subsection{The Poetry and Essay of Health Care}

The Huangzhou times, Su Dongpo "the creation of poetry and essay more than and 740 " [17], which 《before and after the Chibi $\mathrm{Fu} 》$ represented by $\mathrm{Fu}$, in 《stories at Chibi》 as the representative of the word, with 《Dongpo eight》 as the representative of the poem, and in 《Edward Temple tour $\rangle$ as the representative of the essay, were superior in the word, although after thousands of years, is still held in near veneration by the literary world. Huangzhou period of Su Dongpo poetry and Fu of health care, there are two main.

One is optimistic in the face of distress. Because of Su Dongpo's preference, the world in the hearts of identity: Su Dongpo in Huangzhou, or in person to work in Dongpo, or swim in the landscape, or cut firewood and fish in anyway, or focus on the Buddha's enlightenment. , or sing and booze, all is the innate wisdom and open-minded personality dictates. However, at the beginning and that time all was Su Dongpo had to do. In order to support the family, he had to work in Dongpo; when confined to the political, all official fear to contact with him, he had to turn to the landscape lonely, cut firewood and fish in anyway, focus on the Buddha's enlightenment; to open the vent depressed, but due to the "Wu Tai" before the mirror, he had to talk to the flying Fairy by sing and booze. What is different, soon after, Su Dongpo in Huangzhou, the Buddha of the Buddhist monastic ascetic, Taoism due to natural, by careful empirical, realize that life is short and small, and the reorientation of the value of life, gradually formed Wagner broad-minded temperament. Then, he took the open-minded temperament, deeply into the real life in Huangzhou, write in poetry deeply, and by this way of poetry, made once the suffering of metal into philosophy enjoyed a joyful life. For example, he said in 《Moon Over the West River. are in Huangzhou》night drunk lying on the bridge:"The moonlight shone on the glittering surface of the river, there are clouds in the sky. A few silk light white horse is now bearing high spirited, but I am drinker, wait in the river to unsaddle, just want to fall in this grass in sleep. This stream of life so cute, horse, don't tread the pieces of the moon in the water. I unsaddle pillows, lying asleep in the green Yangqiao, hear the cuckoo, the day is clear ". [18] Again, he said in 《A letter to answer Li Duanshu》:"wearing sandals boating on the river, always focussed on the landscape, along with the fisherman and woodman all day, often because the drink was scolded, so gradually no contacts with outsiders". In the face of what the world considers unpleasant, Su Dongpo in Huangzhou, not only do not worry and angry, but "amuse himself". It can be seen that optimistic was Su Dongpo from the Buddhist going, the Taoist because natural, learned a bad deal the wisdom of 
life. The two is rich in life. Huangzhou period, Su Dongpo often in very ordinary things, by poetry text game, laugh at life, adjust mood, boosting interest in life. For example, in Huangzhou, Su Dongpo "eat very crisp oil nut " [19], ask the seller: "what was the name" , seller said: "this nameless" . Dongpo said, it is called "Why crisp". Again, Huangzhou Pan family sell wine, Dongpo passed and tasted with seller, a little sour, smiled and said: "this is wrong with the water", then to "wrong water" of the wine. There is a poem to prove the point that had to drink Pan "wrong water", now want to eat Liu "Why crisp". [3] Again, Su Dongpo in Huangzhou, visited friends Chen Zao, who liked to receive guests, and loved singer and dancer, his wife Liu fierce and jealousy. Every singer and dancer was present, Liu was hit the wall with a stick, Chen Zao more fear. Dongpo due to play poem, "Chen Jichang is really poor, he doesn't sleep about Buddhism, suddenly heard the hellcat roar, then scared heart empty, even on the crutches away". "Lioness's roar" was became famous. Therefore, Su Dongpo in Huangzhou, had mind open-minded and temperament aloof. This is the health evidence that the noble character of Su Dongpo in Huangzhou times, made the elegant culture rich life and relieve depression, to "strengthen health care practice ". [8]

\section{Conclusion}

"People Original have desires" [20], the natural desire that eye for color, ear for voice, nose for incense, tongue for taste, body for touch, meaning for law, The six kind of desire, will born "natural" [21] seven feelings of anger, happy, think, sad, fear, shock and anxiety. The seven emotions too much or less, will produce internal injuries of seven feeeling, which is "anger injury liver, happy injury heart, thinking injury spleen, sad injury lung, and frightened injury kidney". So, must control the desire to adjust emotion, "desire is not extreme concern in the material above, do not have to let the material allocation of excessive compliance with desire "[20]. From the health perspective, in the early the Northern Song period, Shao Yong in 《All illness》said:"all in love, love light disease also light". Emotional changes and blood running between inside and outside, the germinal endless emotions. Too much or less, will kill people in the invisible, not to try, this is heaven sense. The wise man, does not condone his bad mood, not complaining and sad. Everything with a wide smile, of suffering, is the life the wise man.

Through the death of Su Dongpo of Huangzhou put down, there was no doubt that his spirit has been hit, inner emotions, at the first is bound to be a surge high and sweep forward rolling . However, he did not sink, but not be harmed by the "internal injuries of seven feeling". Because he knows that the bad mood is mire of misery, immersion is tantamount to willing to poison. So, Su Dongpo in Huangzhou, to release depressed and adjust temperament by writing books and painting, lyrics for $\mathrm{Fu}$ and writing poems and essay of elegant culture. Because he is clear, good health, life need art, leisurely, contented and humorous. Because of Su Dongpo in Huangzhou, with the wisdom of life, happy life concept, open-minded pleasure fuck rhyme, which makes him get rid of Ecuador, and gain the achievements of his life of elegant culture peak. The Su Dongpo of Huangzhou during the period of elegant thoughts, worthy of today's floating Society for reference. We study Su Dongpo health care in Huangzhou period, designed to draw people's attention to Su Dongpo's regimen, which is not only to promote Sinology, build a complete Soviet learning system has a positive significance, but also benefit to enhance people's literacy, enhance the spirit of the times, leading people's healthy lives.

\section{ACKNOWLEDGMENT}

Hubei Province College of Humanities and social science research base " EDong education and culture research center " project, project number: 201607303.

\section{REFERENCES}

[1] Liu Zongyuan. YiXin ddeb school. Mu Gengcai and Ma Jiannong are editor in chief . Liu Zongyuan [M]. Beijing: Zhonghua Book Company, 2000:399.

[2] Zhang Yi. Throughout the word only [M]. Changsha : Yuelu publishing house, 2003:49.

[3] Ding Yonghuai, Mei Dasheng, Zhang Shejiao note. Su Dongpo works in Huangzhou's full [M]. Wuhan: Wuhan publishing house, 1996:247512, 20155.

[4] Zhang Zhilie, Ma Defu, Zhou Yukai edited. The complete works of Su Shi (note Collection) [M]. Shijiazhuang: Hebei people's publishing house, 2010:628162816281.

[5] Su Shi wrote. Li Zhiliang notes. The famous Tang and Song Dynasties anthology. Corpus of Su Shi [M]. Zhengzhou: Zhongzhou Classics Publishing House, 2010:139. 138. 139. 
[6] (song) feigun fabricated. Written by Luo Shou Chung. Liang Ximan [M]. Xi'an: SanQin publishing house, 2004:134.

[7] was editor in chief of Zeng Zaozhuang. Su poetry review [M]. Chengdu: Sichuan literature and Art Publishing House, 2000:201.

[8] Xiong Lihu fabricated. Tang and Song Dynasties eight articles essence [M]. Wuhan: Hubei people's publishing house, 2007:503503503503.

[9] Cui Chengyun select notes. This carrier of Su Shi's prose collection [M]. Tianjin: hundred flowers Literature and Art Publishing House, 2009:177177.

[10] (song)He Yuan fabricated. written by Zhang Minghua. ChunZhu news [M]. Beijing: China Publishing House, 1997:84.

[11] Cui Erping selected notes. During the Ming and Qing Dynasties calligraphy Halpin selected papers [M]. Shanghai: Shanghai Bookstore Publishing House, 1995:218.

[12] Su Shi wrote. Dongpo words[M]. Nanjing: Phoenix publishing house, 2013:80, 80.

[13] Jiang Shuzhuo edited. Literature theory integration in Song Dynasty [M]. Beijing: Chinese Social Science Press, 2000:283457.

[14] Mi Fu fabricated. Painting and calligraphy history [M]. Beijing: Chinese bookstore, 2014:42, 42.

[15] San Su wrote. Zeng Zaozhuang and Shu Dagang were editors. All words of San Su, (Fourteenth volumes) [M]. Beijing: Chinese press, 2001:48, 48.

[16] Zhang Minglin etc. The words of eight great men of the Tang and Song Dynasties (Su Shi) [M]. Beijing: Minzu University of China press, 2002:30, 30.

[17] Dongpo Chibi poetry network: http://www. dpcbsc. cn/xinwenht/news_view. asp newsid=5682. ?

[18] Edited by Chen Rujiang and Shi Zhecun, . The classic poetry of Song [M]. Shanghai: Shanghai Bookstore Publishing House, 1999:97.

[19] Zhou Xunchu was chief editor, edited by Ge Weijun, Zhou Zilai and Wang Huabao. the anecdote compilation of Song[M]. Shanghai: Shanghai ancient books publishing house 2014:1611.

[20] Gao Changshan. Translation and annotation of XunZi[M]. Harbin: Heilongjiang people's publishing house, 2002:360360.

[21] Zhou Chuncai. the book of Rites[M]. Beijing: China Federation of book publishing house, 2002:75. 